DE

M E D I C I N A

T R O P I C A L

$\mathrm{DE}$

SÃO PAULO

JOURNAL OF THE SÃO PAULO INSTITUTE OF TROPICAL MEDICINE

(1) Universidade Estadual de Maringá, Programa de Pós-Graduação em Ciências da Saúde, Maringá, Paraná, Brazil

(2) Secretaria Municipal de Saúde, Laboratório de Entomologia Médica, Arapongas, Paraná, Brazil

(3) Universidade Estadual de Maringá, Departamento de Análises Clínicas e Biomedicina, Maringá, Paraná, Brazil

Correspondence to: Kárin Rosi ReinholdCastro

Universidade Estadual de Maringá, Departamento de Pós-Graduação em Ciências da Saúde, Av. Colombo, 5790, CEP 87020-900, Maringá, PR, Brazil Tel: +554430114878

Fax: +554430111376

E-mail: karindecastro@yahoo.com.br

Received: 11 January 2017

Accepted: 13 April 2017

\section{Disseminated cutaneous leishmaniasis caused by Leishmania braziliensis in Southern Brazil}

\author{
Norberto Assis Membrive ${ }^{1,2}$, Flávio Jun Kazuma², Thaís Gomes Verzignassi \\ Silveira $^{3}$, Jorge Juarez Vieira Teixeira ${ }^{3}$, Kárin Rosi Reinhold-Castro', Ueslei \\ Teodoro $^{3}$
}

\section{ABSTRACT}

The authors report a case of disseminated cutaneous leishmaniasis caused by Leishmania (Viannia) braziliensis, in a 55 years old patient with 1,119 lesions distributed throughout the body. The patient resides in Sabáudia municipality, North of Paraná State, Southern Brazil, where there was no previous report of this form of leishmaniasis. Treatment with meglumine antimoniate was successful, although the diagnosis was made only five months later.

KEYWORDS: Leishmania (Viannia) braziliensis. Disseminated cutaneous leishmaniasis. Paraná State, Brazil.

\section{INTRODUCTION}

Leishmaniases are infectious diseases caused by protozoa of the genus Leishmania, with a wide spectrum of clinical manifestations, depending on the species of Leishmania involved ${ }^{1}$. Originally, leishmaniases were considered wild zoonoses, but have been reported in rural and urban areas where domestic animals, especially dogs, have been often diagnosed with Leishmania infection ${ }^{2}$

Disseminated cutaneous leishmaniasis (DL) caused by Leishmania (Viannia) braziliensis and Leishmania (Leishmania) amazonensis is a rare form of clinical manifestation and accounts for approximately $2 \%$ of the reported cases of cutaneous leishmaniasis (CL) in Brazil ${ }^{2}$. Torres ${ }^{3}$ reported the first case of DL caused by $L$. (V.) braziliensis in the State of Bahia, Brazil. In 1986, Costa et al. ${ }^{4}$ published the first case of CL. Since then, just a few cases ${ }^{5}$ of DL, with additional research on the parasites characteristics, their immunological behavior and response of patients to treatment ${ }^{2,5}$ have been reported. DL is characterized by expressing multiple papular acneiform lesions, compromising exposed areas, such as limbs, and frequently face and trunk ${ }^{2,4,5}$. The number of lesions can reach hundreds, according to the Ministry of Health ${ }^{2}$.

Another atypical form of CL, known as difuse cutaneous leishmaniasis (DCL) or anergic-DCL, caused by $L$. (L.) amazonensis ${ }^{2}$, was first reported by Silva ${ }^{6}$, in Brazil, and Convit ${ }^{7}$, in Venezuela. DCL is characterized by the presence of multiple non-ulcerated nodular lesions, weak response of T-cells to antigens of Leishmania parasites (amastigotes) and a large number of Leishmania inside macrophages $^{8}$. DCL is also rare, with 1 or 2 cases diagnosed per year and the number of lesions can, as well, reach the hundreds ${ }^{2,8}$. These two clinical forms, DL and DCL, were precisely compared and differentiated based on reported cases by Hashiguchi et al. ${ }^{9}$. 
This report deals with a case of DL in an inhabitant of Vila dos Crentes, a rural town in the municipality of Sabáudia, North of Paraná State, Southern Brazil, showing an extraordinary number of cutaneous lesions.

\section{CASE REPORT}

At the beginning of March 2015, the patient, a 55 years old driver, observed a lesion on the anterior surface of his leg, with a granular bottom and raised edges. After approximately three months of development of the primary lesion, small lesions appeared on the face and thereafter throughout the body (scalp, all the face, neck, arms, hands, including the palms, legs and the dorsal part of the foot), except in the palms surface and genital organ, totaling 1,119 lesions, counted with the a manual counter (Hand Held). The disease was identified five months after the onset. During this period, the patient had lost about $15 \mathrm{~kg}$. When the first lesion appeared, the patient initially received an unsuccessful treatment for allergy. Thereafter, he was treated with six ampoules of penicillin $\mathrm{G}$ benzathine $1,200,000 \mathrm{IU}$, and had unsuccessful results once again. It is noteworthy that the municipality of Sabaúdia is located in the important center of Ivai-Pirapó from the circuit Paraná-Paranapanema of CL incidence, in the NorthCentral mesoregion of Paraná State ${ }^{10}$.

\section{Evolution of the case and laboratory examination}

The patient fail to respond to treatment within three months of the disease onset, then he sought medical resources in the municipality of Arapongas, Paraná, where he was subjected to the following tests: V.D.R.L., negative; FTA-Abs IgG and IgM, negative; Herpes simplex Virus anti-IgG, positive $(23.8 \mathrm{U} / \mathrm{mL})$; Herpes simplex Virus antiIgM, negative; Rubella anti-IgG, positive $(73.7 \mathrm{IU} / \mathrm{mL})$; Rubella anti-IgM, negative; Aspartate Aminotransferase (AST), normal; Alanine Aminotransferase (ALT), normal; Lactic dehydrogenase (LDH), normal; Gamma Glutamyl Transferase, normal; Alpha 1-Acid Glycoprotein, increased $164 \mathrm{mg} / \mathrm{dL}$; Hepatitis B, negative; Hepatitis C, negative; Brucella anti-IgG and IgM, negative; Chlamydia trachomatis anti-IgG, reagent (1/80); Chlamydia trachomatis anti-IgM, negative; Complete blood count, normal; Anti-HIV, negative. The biopsy, performed in a private laboratory, showed the absence of viral infection, a favorable morphologic pattern in the diagnosis of a staphylococci and screening for fungi negative. The indirect immunofluorescence test (IIF) for Leishmania, held in another laboratory was negative. This examination was performed with a kit containing $L$. $(L$.) infantum, for diagnosis of visceral

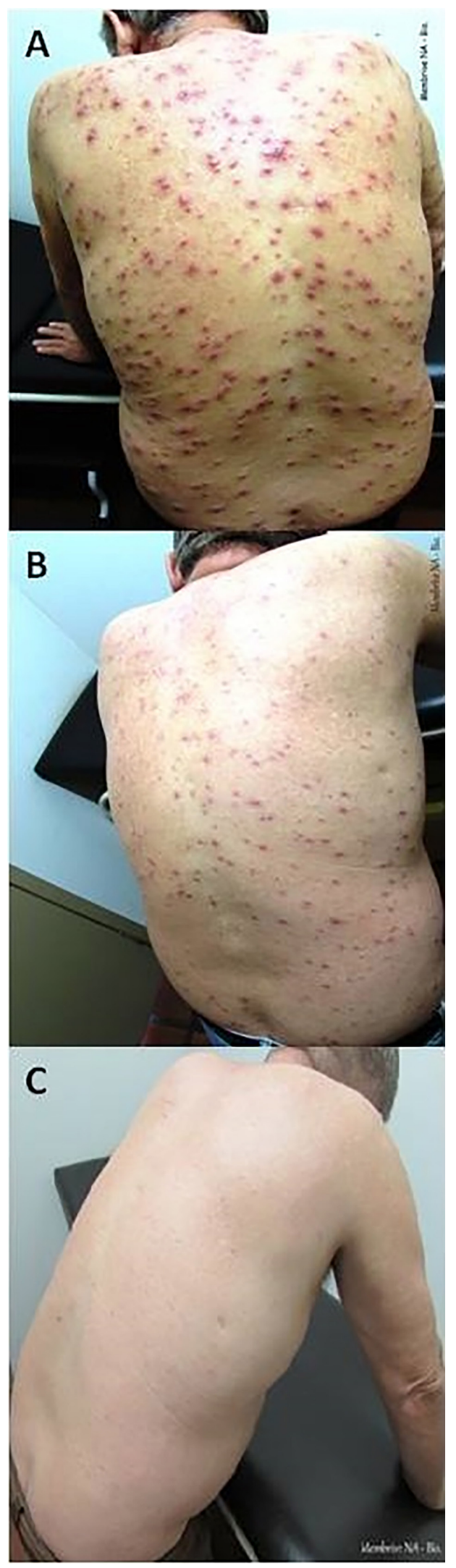

Figure 1 - Patient with disseminated leishmaniasis. (A) Disseminated lesions before treatment; (B) After treatment with 60 ampoules of Glucantime ${ }^{\circledR}$; (C) After treatment with 120 ampoules of Glucantime ${ }^{\circledR}$ 
leishmaniasis. Finally, after 5 months, the patient was sent to an infectious disease specialist of the Laboratory of Medical Entomology from the city of Arapongas, and amastigote forms of Leishmania were detected via direct search (DS) of material collected from the primary lesion of the right leg and three other lesions (face, abdomen, and back). Lesion aspirates were mixed with a saline solution containing penicillin $\mathrm{G}$ potassium (Sigma) $(25,000 \mathrm{IU} / \mathrm{mL})$, and streptomycin (Sigma) $(2 \mathrm{mg} / \mathrm{mL})$, at $4{ }^{\circ} \mathrm{C}$ for $24 \mathrm{~h}$; later they were incubated in 199 medium, containing $10 \%$ of inactivated fetal bovine serum at $25^{\circ} \mathrm{C}$ and the presence of the parasite was detected after five days. It was isolated in the Laboratory of Leishmaniasis from Universidade Estadual de Maringá (UEM) and was sent to Coleção de Leishmania do Instituto Oswaldo Cruz (CLIOC), Rio de Janeiro, Brazil, for identification. The parasite was identified as $L$. (V.) braziliensis (IOC-L 3636).

After the diagnosis, the patient was treated with intravenous Glucantime ${ }^{\circledast}$ (Sanofi-Aventis Farmacêutica Ltda.), $20 \mathrm{mg} / \mathrm{kg} /$ day for 20 days (August 7, 2015, to August 26, 2015). The patient showed a great improvement, with partial healing of lesions, requiring more 20 days of treatment (August 27, 2015, to September 9, 2015), according to the above described procedure. In total, 120 ampoules of glucantime were used. The patient was discharged and showed clinical cure one month after the end of treatment.

\section{DISCUSSION}

The extraordinary number of 1,119 lesions observed in the patient is the most important fact in this case. The parasite was identified in the CLIOC as $L$. (V.) braziliensis, confirming that most of the DL cases described in Brazil are associated with this species of Leishmania ${ }^{4,11}$. In Paraná State, the occurrence of human and canine-CL cases is mainly attributed to infection by $L$. (V.) braziliensis ${ }^{12}$.

The current case draws attention to the number of lesions compared to other cases described in Brazil and in the Southern region, given that the cases of CL have been reported almost exclusively in the North and Northeast of Brazi1 $^{4,5,11}$. In Maranhão State, Galvão et al. ${ }^{5}$ reported a patient with 58 lesions; Carvalho et al. ${ }^{8}$, in the State of Bahia, found in eight patients, a number of lesions ranging from 75 to 800 . Turetz et al. ${ }^{11}$, also in Bahia, described 42 cases of DL, with the number of lesions ranging from 10 to 300 . They drew attention to the increase in the number of patients with DL, classifying it as an emerging form of leishmaniasis, with distinct clinical forms, associated with agricultural activities and the immune response of the host ${ }^{11,13}$. Nevertheless, there is evidence that isolates of $L$. (V.) braziliensis- from DL patients differ genotypically from the ones isolated from patients with cutaneous and mucosal leishmaniasis ${ }^{14,15}$, and DL isolates also induce higher inflammatory responses than isolates from CL patients ${ }^{16}$.

The dissemination of the lesions in the studied patient occurred in the third month, starting from the beginning of the first lesion. However, there was no impairment of mucous tissue. DL presents numerous acneiform, papular and ulcerated lesions that may arise abruptly, suggesting the hematogenous or lymphatic dissemination of the parasite ${ }^{11}$. Usually, the finding of amastigote forms of Leishmania on DS for the diagnosis of DL is low ${ }^{2,13}$, but in this case, the number of amastigote forms of Leishmania detected on DS was abundant, although the disease had appeared 150 days before being confirmed. The patient's weight loss $(15 \mathrm{~kg})$ is not something new, given that fever, general malaise, muscle pain and especially weight loss-are reported among the various systemic manifestations of DL $2,5,11$.

Despite biopsy and IIF negative results, the abundant amastigote forms found in the sample collected from lesions and the rapid development in culture medium were decisive factors for the fast and accurate diagnosis of the current DL case. Treatment with meglumine antimoniate was successful, and the response to the medication was quick, given that the patient had the DL diagnosis after five months from the onset of the first lesion. It is noteworthy that the patient did not exhibit any signs of recurrence of -disease until June 2016, nine months after the end of the treatment.

In addition to the extraordinary number of cutaneous lesions, which motivated this case report, the difficult path search for treatment by the patient, who lived in an important endemic area of TL should be pointed. It shows clearly the lack of preparation of the staff working in the Brazilian health system, mainly concerning vector-borne diseases like leishmaniasis.

\section{REFERENCES}

1. World Health Organization. Leishmaniasis. Geneva: WHO; 2016. [cited 2017 Apr 12]. Available from: http://www.who.int/ leishmaniasis/en/

2. Brasil. Ministério da Saúde. Secretaria de Vigilância em Saúde. Departamento de Vigilância Epidemiológica. Guia de vigilância epidemiológica. $7^{\mathrm{a}}$ ed. Brasília: Ministério da Saúde; 2009.

3. Torres O. A leishmaniasis na Bahia. Arq Bras Med. 1920;7:374425.

4. Costa JM, Marsden PD, Llanos-Cuentas EA, Netto EM, Carvalho EM, Barral A, et al. Disseminated cutaneous leishmaniasis in a field clinic in Bahia, Brazil: a report of eight cases. J Trop Med Hyg. 1986;89:319-23. 
5. Galvão CE, Silva AC, Saldanha AC, Silva CM, Costa MR, Costa JM. Leishmaniose cutânea disseminada produzida por Leishmania viannia braziliensis no Estado do Maranhão Brasil.. Rev Soc Bras Med Trop. 1993;26:121-3.

6. Silva F. Forma raríssima de leishmaniasis tegumentar. Leishmaniose dérmica não ulcerada em nódulos extensas placas infiltradas e hiperpigmentadas. Reunião Anual de Dermato-Sifilógrafos Brasileiros. Rio de Janeiro; 1946.

7. Convit J, Lapenta P. Sobre um caso de leishmaniasis disseminada. Rev Patol Clin (Caracas). 1946;17:153-8.

8. Carvalho EM, Barral A, Costa JM, Bittencourt A, Marsden P. Clinical and immunological aspects of disseminated cutaneous leishmaniasis. Acta Trop. 1994;56:315-25.

9. Hashiguchi Y, Gomez EL, Kato H, Martini LR, Velez LN, Uezato H. Diffuse and disseminated cutaneous leishmaniasis: clinical cases experienced in Ecuador and a brief review. Trop Med Health. 2016;44:2.

10. Monteiro WM, Neitzke HC, Silveira TG, Lonardoni MV, Teodoro U, Ferreira ME. Pólos de produção de leishmaniose tegumentar americana no norte do Estado do Paraná, Brasil. Cad Saude Publica. 2009;25:1083-92.

11. Turetz ML, Machado PR, Ko AI, Alves F, Bittencourt A, Almeida RP, et al. Disseminated leishmaniasis: a new and emerging form of leishmaniasis observed in northeastern Brazil. J Infect Dis. 2002;186:1829-34.
12. Luz E, Membrive N, Castro EA, Dereure J, Pratlong J, Dedet A, et al. Lutzomyia whitmani (Diptera: Psychodidae) as vector of Leishmania (V.) braziliensis in Paraná State, Southern Brazil. Ann Trop Med Parasitol. 2000;94:623-31.

13. Machado PR, Rosa ME, Costa D, Mignac M, Silva JS, Schriefer A, et al. Reappraisal of the immunopathogenesis of disseminated leishmaniasis: in situ and systemic immune response. Trans $\mathrm{R}$ Soc Trop Med Hyg. 2011;105:438-44.

14. Schriefer A, Schriefer AL, Góes-Neto A, Guimarães LH, Carvalho LP, Almeida RP et al. Multiclonal Leishmania braziliensis population structure and its clinical implication in a region of endemicity for american tegumentar leishmaniasis. Infect Immun. 2004;72:508-14.

15. Queiroz A, Sousa R, Heine C, Cardoso M, Guimarães LH, Machado PR, et al. Association between an emerging disseminated form of leishmaniasis and Leishmania (Viannia) braziliensis strain polymorphisms. J Clin Microbiol. 2012;50:4028-34.

16. Leopoldo PT, Machado PR, Almeida RP, Schriefer A, Giudice A, de Jesus AR, et al. Differential effects of antigens from L. braziliensis isolates from disseminated and cutaneous leishmaniasis on in vitro cytokine production. BMC Infect Dis. 2006;6:75. 